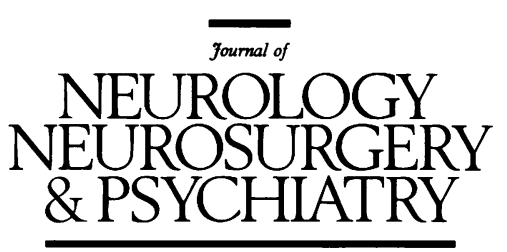

Editorial

\title{
Management of cervical spondylotic myelopathy and radiculopathy
}

Most people older than 50 have cervical spondylosis without any symptoms, apart from a reduced mobility of the cervical spine. In some cases, however, the nerve roots and spinal cord are affected, resulting in cervical spondylotic radiculopathy, cervical spondylotic myelopathy, and combinations of the two. Involvement of nervous tissue is not, however, necessarily accompanied by symptoms. ${ }^{1}$

\section{Pathogenesis, pathology}

The main pathogenetic factors in cervical spondylotic myelopathy and cervical spondylotic radiculopathy were identified in the $1960 \mathrm{~s}$ and $1970 \mathrm{~s},{ }^{1-6}$ and although more recent reviews have provided a better overall picture, ${ }^{7-12}$ only a few new facts have emerged.

A narrowing of the spinal canal in a sagittal direction is still considered to be the most important pathogenetic factor. ${ }^{811} \mathrm{~A}$ bulging or herniated disc, degenerated yellow ligaments, a fixed subluxation due to disc degeneration, and microtraumata may be the cause of compression of the cord, in particular in a constitutionally narrow canal and in deflexion of the neck. ${ }^{2912}$ Hypertrophic facet and uncovertebral joints contribute to cervical spondylotic radiculopathy by occupying the space in the root canal. An acquired anteroposterior diameter of less than 11-12 $\mathrm{mm}$ results in deformation of the cord, the degree of which has been shown to be correlated to the severity of cervical spondylotic myelopathy. ${ }^{13}$ The salient static measurement is, however, the cross sectional area of the cord. Almost all patients with a reduction of $30 \%$ or more do not only show symptoms, but also signs of cord involvement. ${ }^{13} 14$

As well as being a factor in spur formation, neck motion activates symptoms and signs of cervical spondylotic myelopathy. ${ }^{67121415}$ Examples of the part that movement plays can be found in patients with the disease due to athetoid cerebral palsy. ${ }^{16}$ After the studies by Stoltman and Blackwood, ${ }^{17}$ the pathogenetic role of the dentate ligaments in cervical spondylotic myelopathy was considered to be minimal. Miyazaki and Kirita ${ }^{18}$ reported, however, that in Japanese patients with cervical spondylotic myelopathy caused by an ossified posterior longitudinal ligament, the dentate ligaments fix the cord against the anterior part of the canal. In these patients sectioning of the dentate ligaments may spread the tension in the cord over a greater segment. ${ }^{9}$ This report has created a revival of the discussion about the role of these ligaments, and about the value of their sectioning during a posterior surgical decompressive procedure. ${ }^{9}$ The role of ischaemia is still a matter of debate. Distortion and compression of small vessels in the cord may have a pathogenetic influence. ${ }^{3919-21}$ There is no correlation with atherosclerosis of major vessels or with obstruction of blood flow in the anterior spinal artery. ${ }^{82}$ Opinions about the influence of venous stasis also remain controversial. The important role of acute trauma, which is likely to exacerbate any pre-existing myelopathy in a chronically distorted, narrowly confined, cord, ${ }^{8}$ is beyond the scope of this editorial.

Cervical spondylotic myelopathy is a condition in which the spinal cord is damaged, either directly by traumatic compression and abnormal movement, or indirectly by arterial deprivation, venous stasis, or other consequences of the proliferative bony changes that characterise spondylosis. ${ }^{23}$

No recent description of the pathology of cervical spondylosis can compete with the excellent classical descriptions by Hughes. ${ }^{22}$

\section{Clinical syndrome: natural course}

Cervical spondylosis without foraminal or spinal canal stenosis does not result in cervical spondylotic radiculopathy or cervical spondylotic myelopathy. The clinical syndrome of cervical spondylotic myelopathy with spastic weakness of the legs and numb, clumsy hands was extensively described in the $1950 \mathrm{s.}^{24-29}$

Ebara $e t a b^{30}$ distinguish between the amyotrophic type and the myelopathic type of myelopathy hand. The amyotrophic hand presents with localised wasting and weakness of the extrinsic and intrinsic hand muscles, but without remarkable sensory loss or accompanying gait disturbance. It correlates with a reduced transectional area of the spinal cord at the C7-Th1 segments. It is similar to the hand of a patient suffering from spinal muscular atrophy. By contrast, the myelopathic hand shows spastic dysfunction and deficient pain sensation and a reduction in spinal cord diameter at higher levels.

Amyotrophic lateral sclerosis, multiple sclerosis, syringomyelia, and high cervical or cerebral processes are still the most common diagnostic errors, but because of 
magnetic resonance imaging (MRI), it is now easier to detect them preoperatively compared with a decade ago. ${ }^{31-33}$

Clarke and Robinson ${ }^{24}$ reported that once the disorder has been recognised, complete remission to normality never occurs and spontaneous regression is unusual. The commonest pattern of myelopathy, occurring in $75 \%$ of their cases, was one of a series of episodes of new symptoms and signs. In two-thirds of these there was ongoing deterioration between the episodes, whereas in the remaining third the condition stabilised between the periods. Their report has recently been confirmed. ${ }^{723} 29$

There have been hardly any recent reports, however, on the natural course, because most patients are subjected to some form of surgical treatment. Barnes and Saunders ${ }^{34}$ carried out a retrospective study of the natural course in 45 patients, and concluded that those who showed deterioration were more likely to be female, and to have signs of greater cervical mobility. In 1988, LaRocca $^{35}$ summarised the information, then available, on the natural course of the disease. That information does not permit prognostication as there seems to be a variety of clinical courses.

\section{Imaging}

For decades, myelography was the radiological procedure of choice for diagnostic confirmation. It also allowed functional examination, the importance of which was emphasised by Penning, ${ }^{2}$ as it can reveal cord compression in deflexion, particularly at the C3-C4 level. This point has recently been highlighted again..$^{9} 121415213637$

In plain computed tomography (CT), osteophytes and calcified discs are adequately visualised and dimensions of the bony spinal canal measured with accuracy, but the cervical cord and roots cannot be properly assessed. Its role in cervical spondylosis is, therefore, limited. ${ }^{13} 3334$

Computer assisted myelography (CAM) was the next step, but the presence and influence of local excessive movement is not detected by CAM, which does not provide a dynamic perspective of cord compression. When using invasive methods to confirm suspected cervical spondylotic radiculopathy and cervical spondylotic myelopathy, an optimal degree of diagnostic accuracy can, therefore, be obtained by common myelography, followed by CAM. The transverse cord area can then also be measured with the electronic cursor.

Penning et al, in a thorough study on the clinical significance of CAM findings in 80 patients with cervical spondylotic radiculopathy or cervical spondylotic myelopathy, found that concentric compression of the cord in a stenotic canal only produced long tract signs once the cross sectional area of the cord had been reduced by about $30 \%$ to a value of about $60 \mathrm{~mm}^{2}$ or less. ${ }^{14}$

In a comparison of myelography with CT, CAM, and MRI, Brown et al established in 1988 that CAM provides images with excellent spatial and contrast resolution exceeding the accuracy of myelography and CT of the cervical spine..$^{33}$ Comparing CAM with MRI in patients with cervical radiculopathy, the tests achieved equal results in detecting most herniated discs, but CAM was superior to MRI in the detection of osteophytes adjoining herniated discs. Osteophytes without bone marrow are difficult to detect on sagittal and axial T1-weighted scans, because adjacent ligamentous structures and CSF have more or less the same low signal intensity. ${ }^{31-33}$ All osteophytes missed on MRI were seen on plain radiographs, however.

Brown et al concluded that plain radiographs and MRI screening with selective follow up by CAM offer an accu- rate, low-risk, cost-effective strategy for detecting operable lesions in patients with cervical spondylotic radiculopathy and cervical spondylotic myelopathy. The major advantage of CAM is the ability to distinguish bone from soft tissue. ${ }^{33}$

Myelography and CAM are, however, invasive procedures. The complication rate is low, but not negligible. A comprehensive survey revealed that most complications of these invasive techniques could be attributed to cervical spine hyperextension during the procedure and one third occurred in lateral C1-C2 puncture. ${ }^{38}$ With MRI, a non-invasive procedure, the entire cervical canal can be visualised. In intradural lesions with myelopathy, it is more sensitive than any other imaging test.

A combination of plain radiographs of the cervical spine in flexion and extension and surface coil MRI results in a higher percentage of correctly diagnosed spinal canal stenoses, herniated discs, and intradural lesions than can be attained with CAM. ${ }^{31}{ }^{32}$ 39-42 $^{\text {MRI also }}$ reveals whether the most prominent compression in cervical spondylosis is anterior or posterior, allowing the appropriate choice of decompressive surgical treatment. ${ }^{42}$

Technical refinements in software and the scanning technique of MRI have improved its accuracy in evaluating causes of cervical spondylotic myelopathy and in delineating anatomic structures within the lateral root foramina. MRI is as sensitive as CAM in the identification of disease level, but not as specific for type of disease. In combination, however, there is almost complete agreement with surgical findings. Therefore, if MRI quality is suboptimal, or the MRI study inconclusive, selective CT or CAM should be performed.

Currently, all patients with spondylosis and neurological deficit should be subjected to T1-weighted and T2weighted MRI before surgery is even considered..$^{31-33 ~ 39-42}$

\section{Increased signal intensity in the spinal cord}

In 1987, Takahashi et al ${ }^{43}$ were the first to describe areas of increased signal intensity on T2-weighted images of the cord secondary to compression. They considered these areas to be the result of myelomalacia, demyelination, gliosis or microcavities. Others confirmed their findings. ${ }^{4445}$ An intense preoperative signal most probably reflects inflammation or oedema; a mild signal chronic gliosis. Patients with minimal clinical findings but with an appreciably abnormal T2 signal should be considered for surgical decompression. ${ }^{42}$

Matsuda et al ${ }^{45}$ studied the relation between preoperative and postoperative MRI. Patients with areas of increased signal intensity preoperatively were in a worse clinical condition than those without increased signal intensity. The T2 signal abnormality diminished postoperatively in patients who improved clinically. It remained unchanged or increased, however, in those patients who did not improve or who became worse. In patients who show postoperative improvement, an increase in the diameter of the cord may occur. ${ }^{4244-47}$

Postoperative MRI is useful in distinguishing mechanical compression from intrinsic cord damage or atrophy. In many cases, residual cord compression can be shown in patients in whom the surgeon believed he had carried out an adequate decompression. ${ }^{47} 48$ Although CT may indicate a good decompression, cord compression may still appear on T1-weighted MRI. ${ }^{449}$ In 56 cases with a poor outcome after surgery for cervical spondylosis, Clifton et al discovered that alternative diagnoses were eventually established in eight patients. Fifteen patients had cord atrophy, and in 32 cases surgery had failed to decompress the spinal canal adequately. Twenty two of 
the 32 cases underwent a second operation and in nine this significantly improved the result. ${ }^{50}$

MRI should, therefore, be performed after surgery in patients with residual deficit, to detect those who might be considered for a second decompressive procedure. ${ }^{42}$ 48-50

\section{Findings in asymptomatic patients}

There is no doubt that initially CAM, and subsequently MRI are the most important improvements in diagnosis and management of cervical spondylotic myelopathy and cervical spondylotic radiculopathy during the past 15 years. A wide variety of abnormalities seen on CAM or MRI may be asymptomatic, however; these are commonly seen in older patients. Teresi et al, ${ }^{51}$ for example, report that in 100 asymptomatic patients, who were subjected to MRI because of a laryngeal problem, "spinal cord impingement" (a concave defect in the spinal cord adjacent to a site of disk bulging, without obliteration of the subarachnoid space posterior to the cord) occurred in $16 \%$ of patients under 64 years of age, and in $26 \%$ over 64 years. "Cord compression" (with obliteration of the posterior subarachnoid space) was seen in $7 \%$ of patients, but the percentage reduction in cord area in these asymptomatic patients never exceeded $16 \%$. This is in agreement with the findings of Penning et al. ${ }^{14}$ Disc protrusions were seen in $20 \%$ of asymptomatic patients aged $45-54$, and in $57 \%$ of patients older than $64 . .^{51}$

\section{Indication for surgery}

Before a decision to operate is considered diseases such as motor neuron disease and multiple sclerosis must first be ruled out by an experienced neurologist. In some series about $5 \%$ of patients with amyotrophic lateral sclerosis have already undergone cervical operative procedures for presumed cervical spondylotic myelopathy. ${ }^{21}$ The clinical diagnosis should always be supplemented by appropriate imaging, in particular plain radiographs in flexion and extension, in combination with MRI and if necessary CAM. Measurement of cervical mobility on functional radiographs may help to select patients who are more likely to deteriorate and thus more likely to benefit from surgery. The presence of spinal hypermobility enhances the indication for surgical intervention. ${ }^{269122137}$

Patients without major deficits or signs of worsening are probably best treated conservatively and observed over time..$^{391011}$ Those who are moderately or severely disabled on first examination are usually candidates for surgery.

Surgical decompression is indicated in patients with progressive impairment of function without sustained remission..$^{-11}$ Less suitable candidates are those with advanced neurological changes, diabetes, and alcoholism, because of the associated neuropathies, and those too old to engage actively in a postoperative rehabilitation programme." Male patients with signs of prostate enlargement should first be treated for that problem to avoid major postoperative micturition disturbances.

\section{Surgical methods}

Present surgical methods include posterolateral or anterolateral approaches as well as decompression by means of laminectomy, foraminotomy, and neurolysis with and without excision of osteophytes. Open door laminoplasties and vertebral corporectomy have recently been added.

It is obvious from the number and variety of surgical procedures that there is still no single technique that can solve all the diverse neurological and structural problems found in this disorder.

The neurosurgical concept (decompression of root and cord through an anterior or posterior approach) and the orthopaedic concept (immobilisation of the afflicted segment) still form the basis of actual management in cervical spondylotic radiculopathy and cervical spondylotic myelopathy. The results achieved with decompression in cervical spondylotic myelopathy are such, however, that nowadays a greater emphasis is placed on this method of treatment.

\section{POSTERIOR APPROACH}

When performing a surgical procedure involving the contents of the spinal canal, the initial approach was posterior laminectomy or foraminotomy. The proponents of the posterior approach for cervical spondylotic radiculopathy claim the advantages of visualisation of the root, allowing removal of fibrous constrictions around the root and enlargement of the intervertebral foramen. ${ }^{1152-55}$ The often mentioned disadvantage of pain and morbidity can be diminished by use of a microscope and restricted resection of the intervertebral joint without subsequent instability. ${ }^{55}$

In the case of cervical spondylotic myelopathy due to diffuse narrowing of the spinal canal, consensus still suggests that laminectomy is the preferred procedure, provided that there is no kyphosis of the cervical spine. ${ }^{1156}$ Laminectomy must be avoided in patients with straightening or curvature reversal of the cervical spine. The success of laminectomy is dictated by the preservation of cervical lordosis. ${ }^{2115657}$ The preoperative preparation and the posterior operative approach itself have been excellently described by Epstein. ${ }^{11} \mathrm{He}$ prefers to perform in addition a foraminotomy in cases with an associated and significant radiculopathy. This approach, however, may result in the formation of an adverse kyphotic cervical curvature if the foraminotomy is too wide. Laminectomy enlarges the spinal canal but does not reduce the dynamic forces affecting the spinal cord and may actually increase cervical mobility. ${ }^{634}$ To obviate this development, the combination of posterior decompression and Luque rectangle bone fusion has been proposed as a simple, safe, and effective alternative treatment. ${ }^{57}$ It is not yet known how uncomfortable this rigid neck fusion is for the patient.

The posterior approach carries a complication rate of a $2 \%$ to $8 \%$ increase in root and cord deficit. ${ }^{2158}$ The root paralysis after posterior decompression is reported to be of radicular origin and the direct sites of injury are the extradural portions of the anterior and posterior roots. The expanded dural tube pulls the dural tube-root junction posteromedially, exerting traction force on the extradural portion of the anterior and posterior roots. The anterior protrusion of the superior articular process at the lower cervical foramina, together with the higher rate of degeneration with narrowing of the intervertebral foramen, is the reason that the root involvement is usually at the C5-C6 and lower levels. ${ }^{59}$

\section{ANTERIOR APPROACH}

In the 1950s the anterior approach was developed more or less simultaneously by several surgeons. ${ }^{60-64}$ The advantages claimed were simpler and easier decompression of roots and cord with a low instance of perioperative complications, lower morbidity, allowing removal of the disc, and the possibility of implantation of an intradisc transplant, consisting of either bone or synthetic material.

The successful development of the anterior approach 
in cases of cervical spondylotic radiculopathy ${ }^{65-71}$ led to surgeons also trying this technique for anterior decompression in cases of cervical spondylotic myelopathy. 646573

In the case of cervical spondylotic myelopathy the presence of compressive median and paramedian herniated discs and spurs are compelling reasons for anterior decompression, because they cannot usually be removed via a posterior approach, and laminectomy in itself does not decrease pressure caused by anterior compression. ${ }^{11}$ The disc can be partially ${ }^{68-70}$ or completely ${ }^{67} 79$ removed with or without endplates. An argument in favour of partial removal is that after a posterior approach, which entails partial removal of the disc, recurrences are rare. Removal of endplates is not necessary to obtain fusion. ${ }^{68-70}$ The posterior longitudinal ligament and osteophytes may be removed or left intact. Removal of the posterior longitudinal ligament has been considered essential to avoid crushing it between the vertebral bodies; this would result in interscapular pain, or cause cord or root compression. ${ }^{65} 68$

Some series report anterior surgery at more than one level in $30 \%$ to $50 \%$ of cases ${ }^{6672757779}$; others in $10 \%$ only. ${ }^{68} 7076$

\section{REMOVAL OF OSTEOPHYTES}

Whether or not osteophytes should be removed is still a controversial issue. Cloward emphasised the significance of removal of compressive structures. ${ }^{60}$ Initially Bohlman and Emery did not remove osteophytes, ${ }^{21}$ but later they did. Nowadays, some surgeons remove all osteophytes to avoid root compression, when postoperatively the disc height has diminished ${ }^{65670}$; some remove only large osteophytes. Others consider the removal of osteophytes to be dangerous (almost asking for morbidity) and so leave them intact. ${ }^{67} \mathrm{~A}$ survey of the various opinions has been presented by Whitecloud. ${ }^{7496} \mathrm{~A}$ spontaneous reduction in size of the osteophytes has been reported in cases of fusion, ${ }^{79}$ but has never been illustrated by examples. Such a reduction has been refuted by Clifton et al. $^{50}$

\section{FUSION WITH TRANSPLANTS}

The value of introducing a bone transplant between the vertebral bodies to obtain fusion is also debatable. Ilium is the bone most widely used with a fusion rate of between $70 \%$ and $100 \% .{ }^{70} 7779$ There is, however, no relation between the rate of bony fusion and the clinical outcome. ${ }^{697073}$ Non-union or "pseudarthrosis" does not prevent an optimal result. ${ }^{727381}$ Cases have, however, been reported in whom a secondary fusion after a nonunion resulted in an improved outcome. ${ }^{80}$

The most pertinent objection to the use of an ilium transplant is a complaint about persistent pain at the donor site, reported to occur in up to $20 \%$ of patients. ${ }^{72} 75777980$

Bone from the femur head and ilium of human donors and calf bone allotransplant have all been propagated. This obviates the use of autotransplants and the accompanying morbidity. The rate of complications (extrusions, fractures, non-union, and infection) does, however, increase somewhat. ${ }^{77} 79$ Other artificial implants have been prepared from polymethylmethacrylate (PMMA), ${ }^{81-86}$ hydroxylapatite, ${ }^{77}$ and biopolymer. ${ }^{87}$ In a randomised prospective study, the results after six months did not differ from those with an autologous transplant or without a transplant..$^{81} 82$ The use of a transplant, however, reduces the incidence of postoperative radicular pain for the first few weeks.

Some consider it essential to immobilise the neck for a few months with a collar after an anterior operative procedure with or without fusion ${ }^{67} 75$; others are doubtful about its value. ${ }^{666870}$

\section{COMPLICATIONS}

Apart from the common preoperative complications such as myocardial infarction and atelectasis, resulting in a mortality of $0.3 \%$, other more specific complications may occur-for example, erosion of carotid and vertebral arteries, spinal epidural haematoma, oesophageal perforation, lesion of the superior laryngeal nerve and inferior brachial plexus, and sympathetic and hypoglossal nerves. ${ }^{88-93}$ Temporary hoarseness and swallowing difficulties are common. Wound infections and haematomata have all been reported.

Specific damage to the cord and roots with an incidence of between $1 \%$ and $3 \%$ has been reported in most series. ${ }^{90-93}$ If the indication for surgery is cervical spondylotic myelopathy, there is a greater chance of increased cord deficit than in a case of soft disc herniation with cervical spondylotic radiculopathy. ${ }^{63} \mathrm{~A}$ review of complications has been given by Bertalanffy and Eggert. ${ }^{93}$

\section{RESULTS}

The most commonly used classifications for assessing the operative results are still those of Odom et $a l^{94}$ and Nurick. ${ }^{3}$ Recently, the scale of the Japanese Orthopaedic Association, which distinguishes between motor, sensory, and bladder scores, and whose scores range from 4 to 17 points, has become more popular and is now widely used..$^{95} 98106$

Most classifications of survivors use four categories: excellent, good, fair, and poor. The main criterion is the patient's subjective judgement. The problem when comparing the different scales are not the extremes, but the middle ranges. The number of studies reporting the results of the anterior approach in cases of cervical spondylotic radiculopathy ${ }^{65-75}$ by far outnumber those dealing with the posterior approach. ${ }^{52-55}$

The results for cervical spondylotic radiculopathy are better when the cause is a soft disc herniation than in cases of spondylotic radiculopathy and myelopathy. ${ }^{65-70}$ Excellent results are obtained in $80 \%$ to $90 \%$ of cases of disc herniation ${ }^{6369}$ but only in $50 \%$ to $60 \%$ of cases of spondylotic spurs. ${ }^{670}$

Operative results in cervical spondylotic myelopathy are most favourable in those patients in whom the preoperative cord indentation on MRI disappeared completely. ${ }^{47}$

Epstein's ${ }^{1197}$ and Whitecloud's ${ }^{74} 96$ reviews and Hukuda's large series ${ }^{98}$ show that no technique, whether an anterior or posterior operative procedure, has overall superiority, either for cervical spondylotic radiculopathy or cervical spondylotic myelopathy. Age of the patient itself is not an important variable influencing the surgical outcome. ${ }^{96}$

\section{COMPARISON OF ANTERIOR AND POSTERIOR APPROACH}

Comparison of results from series using different surgical procedures is hampered by the fact that many studies have severe methodological shortcomings. Most studies are retrospective; in general they do not mention the duration of preoperative complaints and the outcome is classified by the surgeon with different scales, sometimes on the basis of an inquiry by letter; the duration of follow up is not mentioned, or only the mean is reported. Moreover, the preoperative examination and the duration of symptoms and signs vary, as do the imaging techniques. In some studies, conservative treatment is continued for months or even years, whereas in others surgery is performed after the first consultation. Only a few 
prospective studies have been carried out, ${ }^{5480}$ but no real clinical trials. In summary, it is my view that the published data do not reveal one method to be better than another. ${ }^{10757779}$ If a specific choice has to be made, the decision about the type of surgical approach should preferably be based on detailed biomechanical considerations. ${ }^{911}$

\section{RECENT NEW SURGICAL METHODS}

Dissatisfaction with the standard procedures is implied in the reports of new ones. Partial vertebrectomy allows more radical anterior decompression over a number of motion segments. This procedure, also designated as somatectomy and central corpectomy, in combination with strut grafting, was introduced about a decade ago. Since then, various publications have reported a seemingly better outcome than obtained with laminectomy or the classical anterior decompressive procedure involving interbody fusion. ${ }^{100-106} \mathrm{~A}$ postoperative improvement has been claimed in $70 \%$ to $80 \%$ of cases; however, the perioperative complication rate of $47 \cdot 5 \%$, with a $7 \cdot 5 \%$ rate of persistent sequelae in the form of a radiculopathy reported by Saunders et al in a series of 80 patients ${ }^{107}$ is a severe disadvantage of this method. Other authors state that worsening of myelopathy was not seen. ${ }^{104-106}$ Nevertheless, the high complication rate of this procedure, reported by some authors, is a disadvantage to its widespread introduction. These new procedures such as corporectomies, trench operations, and extensive fusion procedures should only be undertaken by those adequately trained and expert in their execution.

\section{Ossification of the posterior longitudinal ligament}

In Japan, laminoplasty with enlargement of the spinal canal has become the procedure of choice for myelopathy secondary to ossification of the posterior longitudinal ligament. In open laminoplasties and laminectomies, the dorsal surfaces of the dural tube are directly covered by paravertebral muscles. In the various types of closed laminoplasty spaces of various size are left open posterior to the dural tubes according to the angles of opened laminae. ${ }^{989} 104$ It is claimed that these open spaces diminish the chance of subsequent myelopathy due to traction by fibrosis. A correlation was found between a positive clinical result and an increase in the postoperative size of the cord, but not necessarily with the size of the canal.

Laminectomy and laminoplasty do not adequately decompress anterior pressure points. The surgical management of ossification of the posterior longitudinal ligament and cervical spondylotic myelopathy is not identical. In ossification of the posterior longitudinal ligament, the anterior approach poses a greater risk to the dura mater ${ }^{11}$; cases have more intrinsic stability, thus allowing for more extensive posterior decompression.

\section{Accept the natural course or perform surgery?}

In most cases of cervical spondylotic radiculopathy the results of conservative treatment are so rewarding that surgery should not be considered unless pain persists for a few months or unless there is progressive neurological deficit.

Surgical treatment of cervical spondylotic radiculopathy due to the herniation of a soft cervical disc is so successful nowadays, however, that most patients and doctors prefer surgery to prolonged conservative management. A prospective randomised trial to compare continued conservative treatment with surgery in the case of cervical spondylotic radiculopathy due to a soft herniated disc is therefore hardly necessary and would be difficult to organise. ${ }^{8}$

The results in cases of cervical spondylotic radiculopathy due to an osteophyte are less good. The patient should be adequately informed about the uncertainty of the result and about the complication rate before operative decompression is performed. Surgical fusion, the attempt to immobilise the afflicted segment, is in my experience and based on published reports, a superfluous procedure in these cases of cervical spondylotic radiculopathy.

Most favourable reports on cervical spondylotic myelopathy suggest that less than two thirds of the patients with cervical spondylotic myelopathy subjectively improve after surgery by either an anterior or posterior approach, with or without fusion. ${ }^{9106573}$ In a carefully selected series Jeffreys reported improvement in $80 \%$ of patients. ${ }^{109}$ Epstein and Epstein stated in a comprehensive review that $68 \%$ of patients improved after laminectomy, $73 \%$ after anterior surgery, and $85 \%$ after laminectomy and removal of osteophytes, but no information is provided about the methods to assess outcome. ${ }^{97}$ Most series, however, report lower percentages, and include patients who were worse after surgery. 32373109

Is this an improvement compared with the natural course? Is the subjective benefit due to psychological support, to immobilisation of the neck, or due to the physical treatment? It remains to be established whether and when surgical treatment can reliably do more than maintain the status quo, ${ }^{8-10}$ and even this is uncertain.

Patients with cervical spondylotic myelopathy do not form a homogeneous group. Prospective studies are required for the purpose of gathering data on spinal cord dimensions, neurological state, age of patient, levels of spondylotic involvement, and duration of symptoms in relation to the natural course of the disease. It might then be possible to delineate individual syndromes, each with its own natural history.

Subsequently a comparison of the results between specific surgical approaches and conservative management might be performed as a multicentre, multinational, randomised, prospective trial. The need for such a trial has been expressed more than once during the past few years. ${ }^{101223}$ As the author of this survey, I wholeheartedly support this view.

R BRAAKMAN Udenhoutseweg 10, 5056 PE Berkel-Enschot, The Netherlands

I thank Arthur Staal for his valuable comments and Mrs B Vollers-King for editing the text for language.

1 Pallis C, Jones AM, Spillane JD. Cervical spondylosis: incidence and implications. Brain 1954;77:274-89.

2 Penning L. Functional pathology of the cervical spine. Amsterdam: Excerpta Medica, 1968.

3 Nurick S. The natural history and the results of surgical treatment of the spinal cord disorder associated with cervical spondylosis. Brain 1972; 95:101-8.

4 Brain DM, Wilkinson M. Cervical spondylosis. London: Heinemann, 1967.
5 Reid JD. Effects of flexion-extension movements of the head and spine upon the spinal cord and nerve roots. $\mathcal{F}$ Neurol Neurosurg Psychiatry 1960;23:214-21.

6 Adams CBT, Logue V. Studies in cervical spondylotic myelopathy. II The movement and contour of the spine in relation to the neural complications of cervical spondylosis. Brain 1971;94:569-86.

7 Maurice-Williams RS. Spinal degenerative disease. Bristol: Wright and Sons, 1981.

8 Monro P. What has surgery to offer in cervical spondylosis? In: Warlow $\mathrm{CH}$, Garfield J, eds. Dilemmas in the management of the neurological patient. Edinburgh: Churchill Livingstone, 1984.

9 Cusick JF. Pathophysiology and treatment of cervical spondylotic myelopathy. Clin Neurosurg 1991;37:661-81.

10 Uttley D, Monro P. Neurosurgery for cervical spondylosis. Br $\mathcal{f}$ Hosp Med 1989;42:62-70.

11 Epstein JA. The surgical management of cervical spinal stenosis, spondylosis, and myeloradiculopathy by means of posterior approach. Spine 1988;13:864-9. 
12 White III AA, Panjabi MM. Biomechanical considerations in the surgical management of cervical spondylotic myelopathy. Spine 1988;13:856-60.

$13 \mathrm{Yu}$ YL, du Boulay GH, Stevens JM, et al. Computed tomography in cervical spondylotic myelopathy and radiculopathy; visualisation of structures, myelographic comparison, cord measurements and clinical utility. Neuroradiology 1986;28:221-36.

14 Penning L, Wilmink JT, Van Woerden HH, et al. CT-myelographic findings in degenerative disorders of the cervical spine: clinical significance. Am $\mathcal{F}$ Neuroradiol 1986;7:119-27.

15 Robinson RA, Afeiche N, Dunn EJ, et al. Cervical spondylotic myelopathy: etiology and treatment concepts. Spine 1987;2:89-99.

16 Nishihara N, Tanabe G, Nakahara S, et al. Surgical treatment of cervical spondylotic myelopathy complicating athetoid cerebral palsy. I Bone foint Surg 1984;66B:504-8.

17 Stoltmann HF, Blackwood W. An anatomical study of the role of the dentate ligaments in the cervical spinal canal. $\mathcal{F}$ Neurosurg $1966 ; 24: 43-6$.

18 Miyazaki K, Kirita Y. Extensive simultaneous multisegmental laminec tomy for myelopathy due to ossification of the posterior longitudinal ligament in the cervical region. Spine 1986;11:531-42.

19 Breig A. Biomechanics of the central nervous system. Chicago: Year Book Medical, 1960.

20 Gooding MR, Wilson CB, Hoff JT. Experimental cervical myelopathy: effects of ischemia and compression of the canine cervical spinal cord. $\mathcal{F}$ Neurosurg 1975;43:9-17.

21 Bohlman HH, Emery SE. The pathophysiology of cervical spondylosis and myelopathy. Spine 1988;13:843-7.

22 Hughes JT. Pathology of the spinal cord. London: Lloyd Luke, 1978.

23 Rowland LP. Surgical treatment of cervical spondylotic myelopathy: time for a controlled trial. Neurology 1992;42:5-13.

24 Clarke E, Robinson PK. Cervical myelopathy. A complication of cervical spondylosis. Brain 1956;79:483-5

25 Lees F, Aldren-Turner JW. Natural history and prognosis of cervical spondylosis. $B M F$ 1963;92:1607-10.

26 Nurick S. The natural history and the results of surgical treatment of the spinal cord disorder associated with cervical spondylosis. Brain 1972;95:101-8.

27 Phillips DG. Upper limb involvement in cervical spondylosis. $f$ Neurol Neurosurg Psychiatry 1975;38:386-90.

28 Symon $L$, Lavender $P$. The surgical treatment of cervical spondylotic myelopathy. Neurology 1967;17:117-21.

29 Voskuhl RR, Hinton RC. Sensory impairment in the hands secondary to spondylotic compression of the cervical spinal cord. Arch Neurol 1990;47:309-11.

30 Ebara S, Yonenobu K, Fujiwara F, et al. Myelopathy hand characterized by muscle wasting. Spine 1988;13:785-91.

31 Enzman DR, de la Paz RL, Rubin JB. Magnetic resonance of the spine. St Louis: The CV Mosby Company, 1990.

32 Atlas SW. Magnetic resonance imaging of the brain and spine. New York: Raven Press, 1991.

33 Brown BM, Schwartz RH, Frank E, et al. Preoperative evaluation of cervical radiculopathy and myelopathy by surface-coil MR Imaging. Am $\mathcal{F}$ Neuroradiol 1988;9:859-66.

34 Barnes MP, Saunders M. The effect of cervical mobility on the natural history of cervical spondylotic myelopathy. $\mathcal{F}$ Neurol Neurosurg Psychiatry 1984;47:17-20.

35 LaRocca $\mathrm{H}$. Cervical spondylotic myelopathy: natural history. Spine 1988;13:854-5

36 Fukui K, Kataoka O, Sho $\mathrm{T}$, et al. Pathomechanism, pathogenesis and results of treatment in cervical spondylotic myelopathy caused by dynamic canal stenosis. Spine 1990;15:1148-52.

37 Kallen F, Simmons EH, Marzo JM. Recognition of cervical spondylotic myelopathy using plain lateral $X$-rays [thesis]. Buffalo, New York: Department of Anatomical Sciences and Orthopaedics. School of Medicine State University of Buffalo, 1986.

38 Robertson HJ, Smith RD. Cervical myelography: survey of modes of practice and major complications. Radiology 1990;174:79-83.

39 Larsson EM, Holtas S, Cronqvist S, et al. Comparison of myelography, CT myelography and magnetic resonance imaging in cervical spondylosis and disk herniation. Acta Radiol 1989;30:233-9.

40 Nagata, K, Kiyonaga $K$, Ohashi $T$, et al. Clinical value of magnetic resonance imaging for cervical myelopathy. Spine 1990;15:1088-96.

41 Statham PF, Hadley DM, Macpherson P, et al. MRI in the management of suspected cervical myelopathy. $\mathscr{f}$ Neurol Neurosurg Psychiatry 1991;54:484-9.

42 Mehalic ThF, Pezzuti RT, Applebaum BI. Magnetic resonance imaging and cervical spondylotic myelopathy. Neurosurgery 1990;26:217-27.

43 Takahashi M, Sakamoto Y, Miyawaki M, et al. Increased MR signal intensity secondary to chronic cervical cord compression. Neuroradiolog 1987;29:550-6.

44 Haupts M, Haan J. Further aspects of MR-signal enhancements in stenosis of the cervical spinal canal. MRI investigations in correlation to clinical and CSF findings. Neuroradiology 1988;30:545-6.

45 Matsuda Y, Miyazaki K, Tada K, et al. Increased MR signal intensity due to cervical myelopathy. Analysis of 29 surgical cases. $\mathcal{F}$ Neurosurg 1991; 74:887-92

46 Ross JS, Masaryl ThJ, Modic MT. Postoperative cervical spine: MR assessment. F Comput Assist Tomogr 1987;11:955-62.

47 Harada A, Mimatsu K. Postoperative changes in the spinal cord in cervical myelopathy demonstrated by magnetic resonance imaging. Spine 1992;17:1275-80.

48 Batzdorf U, Flannigan BD. Surgical decompressive procedures for cervical spondylotic myelopathy. A study using MRI. Spine 1991;16:123-7.

49 Okamoto A, Shinomiya K, Furuya K, et al. Postoperative magnetic resonance imaging in patients with cervical myelopathy. Spine 1991;16: 530-4.

50 Clifton AG, Stevens JM, Whitear P, et al. Identifiable causes for poor outcome in surgery for cervical spondylosis. Post-operative computed myelography and MR imaging. Neuroradiology 1990;32:450-5.

51 Teresi LM, Lufkin RB, Reicher MA, et al. Asymptomatic degenerative disk disease and spondylosis of the cervical spine: $M R$ imaging. Radiology 1987;164:83-8.

52 Frykholm R. Cervical nerve root compression resulting from disc degeneration and root-sleeve fibrosis. Acta Chir Scand 1951;160:1-147.

53 Henderson FM, Hennessy RG, Shuey HM, et al. Posterior-lateral foraminotomy as an exclusive operative technique for cervical radiculopathy: a review of 846 consecutively operated cases. Neurosurgery 1983;13:504-12.

54 Fager CA. Posterolateral approach to ruptured median and paramedian cervical disk. Surg Neurol 1983;20:443-52.

55 Aldrich F. Posterolateral microdiscectomy for cervical monoradiculopathy caused by posterolateral soft cervical disc sequestration. $\mathcal{F}$ Neurosurg 1990;72:370-7.

56 Braakman R. Cervical spondylotic myelopathy In: Krayenbuhl $\mathrm{H}$, ed Advances and technical standards in neurosurgery. Wien:Springer, 1979.

57 Maurer PK, Ellenbogen RG, Ecklund J, et al. Cervical spondylotic myelopathy: treatment with posterior decompression and Luque rectangle bone fusion. Neurosurgery 1991;28:680-4.

58 Polkey CE. The immediate effects of cervical and upper dorsal laminectomy and facetectomy. $\mathcal{F}$ Neurol Neurosurg Psychiatry 1984;47:106-9.

59 Hayashi K, Tabuchi K, Yabuji T, et al. The position of the superior articular process of the cervical spine. Its relationship to cervical spondylotic ular process of the cervical spine. Its relation

60 Cloward RB. The anterior approach for removal of ruptured cervical disks. I Neurosurg 1958;15:602-17.

61 Smith GW, Robinson RA. The treatment of certain cervical spine disorders by anterior removal of the intervertebral disc and interbody fusion. f Bone foint Surg 1958;40A:607-24.

62 Bailey RW, Badgley CE. Stabilization of the cervical spine by anterio fusion. F Bone foint Surg 1960;42A:565-94

63 Hirsch C. Wickbom I, Lidström A, et al. Cervical-disc resection. $\mathcal{F}$ Bone Foint Surg 1964;46A:1811-21.

64 Verbiest H, Paz Y, Geuse HD. Anterolateral surgery for cervical spondylosis in cases of myelopathy or nerve root compression. $\mathcal{f}$ Neurosurg 1966;25:611-8

65 Bertalanffy H, Eggert HR. Clinical long-term results of anterior cervical discectomy without fusion for treatment of cervical radiculopathy and myelopathy. Acta Neurochir (Wein) 1988;90:127-35.

66 Cuatico W. Anterior cervical discectomy without interbody fusion. Acta Neurochir (Wein) 1981;57:269-74.

67 Martins AN. Anterior cervical discectomy with and without interbody bone graft. I Neurosurg 1976;44:290-5.

68 Grisoli F, Graziani N, Fabrizi AP, et al. Anterior discectomy without fusion for treatment of cervical lateral soft tissue disc extrusion: a follow up of 210 cases. Neurosurgery 1989;24:853-9.

69 Murphy MG, Gado M. Anterior cervical discectomy without interbody bone graft. $\mathcal{F}$ Neurosurg 1972;37:71-4.

70 Husag L, Probst Ch. Microsurgical anterior approach to cervical discs. Review of 60 consecutive cases of discectomy without fusion. Acta Neurochir (Wein) 1984;73:229-42.

71 Yamamoto I, Ikeda A, Shibuya N, et al. Clinical long-term results of anterior discectomy without interbody fusion for cervical disc disease. Spine 1991;16:272-9.

72 Lunsford LD, Bissonette DJ, Jannetta PJ, et al. Anterior disc surgery for cervical disc disease. Part 1 . Treatment of lateral cervical disc herniation in 253 cases. $\mathcal{F}$ Neurosurg $1980 ; 53: 1-11$.

73 Lunsford LD, Bissonette DI, Zorub DS. Anterior surgery for cervical disc disease. Part 2. Treatment of cervical spondylotic myelopathy in 32 cases. I Neurosurg 1980;53:12-9.

74 Whitecloud ThS III. Anterior surgery for cervical spondylotic myelopathy Spine 1988;13:861-3.

75 Espersen JO, Buhl M, Eriksen EF, et al. Treatment of cervical disc disease using Cloward's technique. General results, effects of different operative methods and complications in 1106 patients. Acta Neurochir (Wein) 1984;70:97-114.

76 Snyder GM, Bernhardt M. Anterior cervical fractional interspace decompression for

77 Senter HJ, Kortyna R, Kemp WR. Anterior cervical discectomy with hydroxylapatite fusion. Neurosurgery 1989;25:29-43.

78 Hankinson $\mathrm{HL}$, Wilson CB. Use of the operating microscope in anterior cervical discectomy without fusion. $\mathcal{F}$ Neurosurg 1975;43:452-6.

79 Gore D, Gardner GM, Sepic SB, et al. Röntgenographic findings following anterior cervical fusion. Skeletal Radiol 1985;15:556-9.

80 Jamjoon AB, Rawlinson JN, Kirkpatrick JN. Reoperation related to graft complication following anterior cervical fusion. $\mathcal{F}$ Neurol Neurosurg Psychiatry 1990;53:1017.

81 Bent MJ vd, Acker REH v, Meijer J. De anterieure discectomie als behandeling voor een cervicaal radiculair syndroom. Ned Tijdschr Geneeskd 1989;133:1550-4.

82 Bent MJ vd. Anterior fusion of the cervical spine using methylmetacrylate. Erasmus University, Rotterdam, [thesis] 1994.

83 Cantu RC. Anterior spinal fusion using methylmethacrylate (Acrylic) Int Surg 1974;59:110-1.

84 Clark $C R$, Whitehill $R$. Two views of the use of methylmethacrylate for stabilization of the cervical spine. Orthopedics 1989;12:589-96.

85 Zeilstra DJ, Bettag W. Die ventrale zervikale Discektomie und Fusion mit Palacos. In: Bettag W, ed. Neurochirurgie in ausgewählten Kapitteln. Palacos. In: Bettag W, ed. Neurochirurgie

86 Böker DK, Schultheiss R, Probst EM. Radiologic long-term results after cervical interbody fusion with polymethyl-methacrylate (PMMA) Neurosurg Rev 1989;12:217-21.

87 Lozes G, Fawaz A, Cama A, et al. Discectomies of the lower cervical spine using interbody polymer (BOP) implants. Acta Neurochir 1989;96: 88-93.

88 Berge Henegouwen v DP, Roukema JA, Nie de JC, et al. Esophageal perforation during surgery on the cervical spine. Neurosurgery 1991;29: 766-8.

89 Newhouse KE, Lindsay RW, Clark CR, et al. Esophageal perforation following anterior cervical spine surgery. Spine 1989;14:1051-3.

90 Flynn TB. Neurologic complications of anterior cervical interbody fusion. Spine 1982;7:536-9.

91 Sugar O. Spinal cord malfunction after anterior cervical discectomy. Surg Neurol 1981;15:4-8.

92 West CGH. Bilateral brachial paresis following anterior decompression for cervical spondylosis. Spine 1986;11:176-8.

93 Bertalanffy $\mathrm{H}$, Eggert $\mathrm{H}$. Complications of anterior cervical discectomy without fusion in 450 consecutive patients. Acta Neurochir (Wein) 1989;99:41-50. 
94 Odom GL, Finney W, Woodhall B. Cervical disk lesions. $\mathcal{F} A M A 1958$; 166:23-8.

95 Hirabayashi K, Miyakawa J, Stamoki K, et al. Operative results and postoperative progression of ossification among patients with ossification of the posterior longitudinal ligament. Spine 1984;6:354-64

96 Whitecloud ThS III. Management of radiculopathy and myelopathy by the anterior approach. In: Cervical Spine Research Society, ed. The cervical spine. Philadelphia:Lippincott, 1983;411-24.

97 Epstein JA, Epstein NE. The surgical management of cervical spinal stenosis, spondylosis, and myeloradiculopathy by means of the posterior approach. In: Cervical Spine Research Society, ed. The cervical spine. Philadelphia:Lippincott, 1989:625-9.

98 Hukuda S, Mochizuki T, Ogata M, et al. Operations for cervical spondylotic myelopathy. F Bone foint Surg 1985;67B:609-15.

99 Yonenubo K, Hosono N, Iwasaki M, et al. Laminoplasty versus subtotal corpectomy. Spine 1992;17:1281-4.

100 Bernard TN Jr, Whitecloud ThS III. Cervical spondylotic myelopathy and myeloradiculopathy: anterior decompression and stabilisation with and myeloradiculopathy: anterior decompression and stabilisa

101 Boni M, Cherubino P, Benazzof J. Multiple subtotal somatectomy. Technique and evaluation in a series of thirty-nine cases. Spine 1984; 9:358-62.
102 Hanai K, Fujiyoshi F, Kamei K. Subtotal vertebrectomy and spinal fusion for cervical spondylotic myelopathy. Spine 1986;11:310-5.

103 Kojima T, Waga S, Kubo Y, et al. Anterior cervical vertebrectomy and interbody fusion for multi-level spondylosis and ossification of the posterior longitudinal ligament. Neurosurgery 1989;24:864-72.

104 Yonenubo K, Fugi T, Ono K, et al. Choice of surgical treatment for multisegmental cervical spondylotic myelopathy. Spine 1985;10: $710-8$.

105 Zdeblick TA, Bohlman HH. Cervical kyphosis and myelopathy. Treatment by anterior corpectomy and strutgrafting. F Bone foint Surg 1989;71A: $170-82$

106 Okada K, Shirasaki N, Hayashi H, et al. Treatment of cervical spondylotic myelopathy by enlargement of the spinal canal anteriorly, followed by arthrodesis. F Bone foint Surg 1991;73A:352-64.

107 Saunders RL, Bernini PM, Shirreffs TG, et al. Central corpectomy for cervical spondylotic myelopathy: a consecutive series with long-term follow up evaluation. $\mathcal{F}$ Neurosurg 1991;74:163-70.

108 Phillips D Surgical treatment of myelopathy with cervical spondylosis. $\Im$ Neurol Neurosurg Psychiatry 1973;36:879-84.

109 Jeffreys RV. Surgical treatment of cervical myelopathy due to spondylosis and disc degeneration. I Neurol Neurosurg Psychiatry 1986;49: 353-61

\section{Neurological stamp}

\section{Marie François Xavier Bichat (1771-1802)}

Bichat, who lived a short life, helped found the science of histology. The French Revolution, with its many executions by the guillotine (invented by the French physician Joseph Ignance Guillotine), had provided him with a plentiful supply of bodies for dissection. Without the aid of a microscope he identified 20 different "membranes" or tissues and their normal and pathological structure. Among these were nervous, vascular, mucous, serous, and connective tissues. The tissues were considered to be elementary structures which, when weakened, permitted disease to occur. Bichat produced two highly influential works, Traité des membranes (1800) and his five volume Anatomie générale (1801).

The concept of a nervous system in the sympathetic chain of ganglia, independent of the CNS, was first suggested by Bichat. He also had views on contractility, irritability, and toxicity. He is honoured by a stamp issued by France in 1959. (Stanley Gibbons 1432, Scott B334). He died aged 31 from pulmonary tuberculosis.

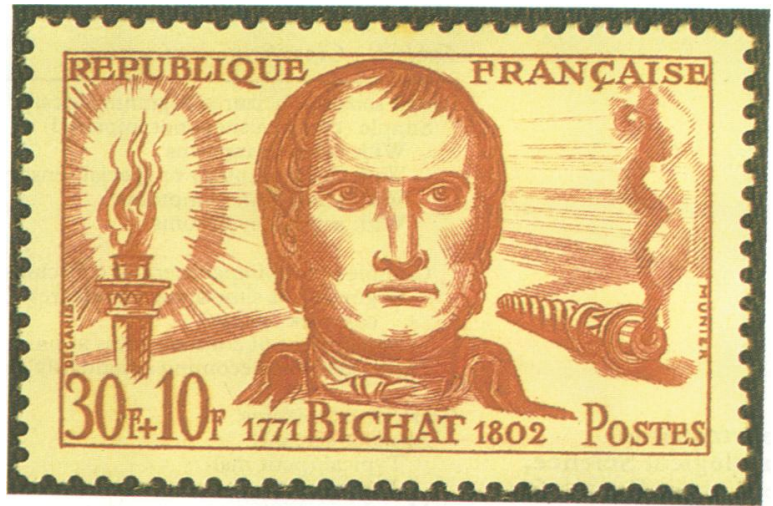

